\title{
Mercury and its effect on human health: a review of the literature
}

\author{
Siti Thomas Zulaikhah ${ }^{1}$, Joko Wahyuwibowo ${ }^{2}$, Arrizki Azka Pratama ${ }^{3}$ \\ ${ }^{1,2}$ Departement of Public Health, Faculty of Medicine, Universitas Islam Sultan Agung Semarang, Indonesia \\ ${ }^{3}$ Faculty of Medicine Universitas Islam Sultan Agung Semarang, Indonesia
}

\begin{abstract}
Article Info
Article history:

Received Feb 6, 2020

Revised Apr 10, 2020

Accepted May 2, 2020

\section{Keywords:}

GSH

Mercury

Oxidatiev stress

ROS

SOD

ABSTRACT

Mercury in human body is a free radical that can cause depletion of glutathione (GSH) and hoarding of $\mathrm{H} 2 \mathrm{O} 2$, leading to shorten the age of erythrocytes and cause haemolysis. Approximately $90 \%$ organic form can be absorbed by the intestinal wall, while inorganic forms are only about $10 \%$. The initial form can also penetrate the blood and placental barrier so that it can cause teratogenic effects and nervous disorders. The effects of mercury toxicity on humans depend on the chemical form of mercury, dosage, age of people exposed, length of exposure, entry into the body, fish diet and consumption of seafood. Mercury is able to bind sulfidril proteins in cells resulting in nonspecific cell injury or even cell death, cessation of microtubule formation, enzyme inhibition, oxidative stress, cessation of protein and DNA synthesis, and autoimmune responses. Classified into a very toxic metal, mercury can trigger the formation of ROS, hydrogen peroxide, lipid peroxidation, hydroxyl radicals that can inhibit enzymes, cell damage, DNA damage, protein structure damage, disruption on the body's antioxidant metabolism, especially superoxide dismutase (SOD) and glutathione peroxidase (GPx). Mercury exposure is associated with an increased risk of hypertension, myocardial infarction, coronary dysfunction, and atherosclerosis. This review is clearly in line to investigate the effect of mercury on human health based on previous research, article and other literature sources.
\end{abstract}

This is an open access article under the CC BY-SA license.

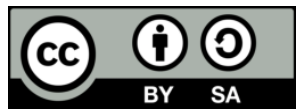

\section{Corresponding Author:}

Siti Thomas Zulaikhah,

Department of Public Health, Faculty of Medicine,

Universitas Islam Sultan Agung Semarang,

Jl. Raya Kaligawe KM. 4 Semarang 50112, Indonesia.

Email: sitithomas@unissula.ac.id

\section{INTRODUCTION}

Mercury contamination occurs through food, drink, breathing, and skin contact. Mercury is the only metal that undergoes biomagnification through the food chain and is very easily transformed into more toxic organic forms (methyl mercury, dimethyl mercury, ethyl mercury, etc.) Mercury is also easily bound by sulfhidril groups wherein the group, and is able to inhibit the function of enzymes that are important for metabolism in the body [1]. Exposure to mercury can have a very varied effect, depending on the level and duration of exposure, age and health status of individuals [2]. Furthermore, it may cause biocomial damage to tissues and genes through various mechanisms such as interfering with intracellular calcium homeostasis, disruption on membrane potential, change on protein synthesis, inhibiting enzymes and disruption of amino acid pathways in the central nervous system [3]. 
Mercury is still widely used in industrial processes, such as industrial thermometers, hydrometers, barometers, sphygmomanometers, florescent lamps, batteries, pesticides, plastics, caustic soda, chlor-alkali, gold mining as well as in laboratories [3-5]. Globally, the largest source of mercury emissions comes from traditional gold mining [5]. The sources of mercury emissions in Indonesia around 57.5\% also come from traditional gold mining with total emissions of around 195 tons / year. In 2010, there were around 900 locations which included around 250,000 workers involved in traditional gold mining using mercury [6]. Gold miners have a high risk of mercury poisoning because they can be exposed continuously. High risk of exposure to mercury during traditional gold processing is during the screening and spawning process. When a screening process occurs, amalgam mixtures that already contain mercury are washed and squeezed. Processors will be exposed to mercury vapour through inhalation because gold ore which has been bound by mercury will be heated at very high temperatures and mercury evaporation occurs in the process of spawning. Mercury vapour inhaled $80 \%$ will be absorbed into the lungs, which then can penetrate the blood barrier of the brain and placenta and distributed throughout the bod $[3,7,8]$. Mercury used in the amalgamation process of $95 \%$ will be released into the environment which results in pollution of water, soil, air, etc. Organic mercury is considered the most dangerous form of exposure to $\mathrm{Hg}$ and most often, it is detected as $\mathrm{MeHg}$, and ethyl mercury $(\mathrm{EtHg})$, found in various sources such as fish, poultry, insecticides, fungicides, pesticides, and vaccines containing thimerosal [9]. About 85\% of ingested methyl mercury is absorbed in the digestive tract, while about $5 \%$ is in the blood and $10 \%$ in the brain. In many developing countries, mercury is still a big problem that requires action for proper control. Many efforts must be made to reduce emissions and prevention of exposure [10].

\section{Natures of mercury}

Mercury is a chemical element with the symbol $\mathrm{Hg}$ and atomic number 80 and atomic weight 200.59. It has a freezing point of $-38.83{ }^{\circ} \mathrm{C}$; a boiling point of $356.73{ }^{\circ} \mathrm{C}$; a density of $13.5956 \mathrm{~g} / \mathrm{cm}^{3}$; relative abundance of $5 \times 10^{-5} \%$; specific heat capacity of $0.1397 \mathrm{~J} / \mathrm{g} / \mathrm{K}$; heat of fusion of $11.807 \mathrm{j} / \mathrm{g}$; heat of evapouration of $59.453 \mathrm{~kJ} / \mathrm{mol}$; thermal conductivity of $1.063 \times 10^{-4} \mathrm{~mm}^{-2}$; thermal expansion coefficient of $1.826 \times 10-4 \mathrm{~K}-1$; electrical conductivity of $1.063 \times 10-4 \mathrm{~mm}-2$; a crystal structure rhombohedral; viscosity of $1.685 \mathrm{mPa} \bullet \mathrm{s}$; and surface tension of $480.3 \times 10-5 \mathrm{~N} / \mathrm{cm}$. Physical and chemical properties of mercury is presented in Table 1.

Table 1. Physical and chemical properties of mercury [11]

\begin{tabular}{lc}
\hline \multicolumn{1}{c}{ Atomic number } & 80 \\
\hline Atomic weight & 200.59 \\
Freezing point, ${ }^{\circ} \mathrm{C}$ & -38.89 \\
Boiling point at $101.3 \mathrm{kPa},{ }^{\circ} \mathrm{C}$ & 357.3 \\
Density at $0^{\circ} \mathrm{C}, \mathrm{g} / \mathrm{cm}^{3}$ & 13.5956 \\
Relative abundance, $\%$ & $5 \times 10^{-5}$ \\
Specific heat capacity at $0{ }^{\circ} \mathrm{C}, \mathrm{J} / \mathrm{g} / \mathrm{K}$ & 0.1397 \\
Heat of fusion, $\mathrm{j} / \mathrm{g}$ & 11.807 \\
Heat of evapouration at $357.3{ }^{\circ} \mathrm{C}, \mathrm{kJ} / \mathrm{mol}^{-2}$ & 59.453 \\
Thermal conductivity at $0{ }^{\circ} \mathrm{C}, \mathrm{m} \Omega^{-1} \mathrm{~mm}^{-2}$ & $1.063 \times 10^{-4}$ \\
Thermal expansion coefficient at $0-100^{\circ} \mathrm{C}, \mathrm{K}-1$ & $1.826 \times 10-4$ \\
Electrical conductivity at $0^{\circ} \mathrm{C}, \mathrm{m} \Omega-1 \mathrm{~mm}^{-2}$ & $1.063 \times 10-4$ \\
Crystal structure & Rhombohedral \\
Viscosity at $0^{\circ} \mathrm{C}, \mathrm{mPa} \cdot \mathrm{s}$ & 1.685 \\
Surface tension, $\mathrm{N} / \mathrm{cm}$ & $480.3 \times 10-5$ \\
\hline
\end{tabular}

\section{Types of mercury}

In general, mercury can be can be classified into three types:

- Elemental $\mathrm{Hg}\left(\mathrm{Hg}^{0}\right) / \mathrm{Metallic}$

Elemental $\mathrm{Hg}(\mathrm{Hg} 0)$ comes from thermostats, thermometers, dental amalgams, and $\mathrm{Hg}$ added to latex paint, to a certain extent entering the atmosphere in a yawning state. The oxidation state of $\mathrm{Hg} 0$ represents the only metal that occurs in a liquid form at room temperature. It plays an important role in serious occupational health problems and in the global cycle of $\mathrm{Hg}$ and can be quickly absorbed through inhalation. Mercury can cross the blood brain barrier and is rapidly oxidized to $\mathrm{Hg} 2$ ions which are maintained in brain cells for years. In most parts of the world, dentists still use dental amalgam processes that contain $\mathrm{Hg}$ elements as the main component [3].

- Inorganic mercury (mercury salt)

In the form of $\mathrm{Hg} 2+$ (mercuric) and $\mathrm{Hg}+$ (Mercurous) is found in laxatives, cosmetic products, plant powders, diuretics, and antiseptics. This can also be induced from $\mathrm{Hg}$ vapour elements or methyl 
mercury (MEHg) metabolism [3]. Among the two stages, the oxidation of $\mathrm{Hg} \mathrm{2+}$ is more reactive. It can form complexes with organic ligands, especially sulfurhidryl groups. For example, $\mathrm{HgCl} 2$ is very soluble in water and very toxic, whereas $\mathrm{HgCl}$ is insoluble and less toxic.

- Organic mercury (Hg organic)

Organic $\mathrm{Hg}$ is considered the most dangerous form of $\mathrm{Hg}$ exposure and most often, it is detected as $\mathrm{MeHg}$, and ethyl mercury (EtHg) [9]. It has been found in various sources such as fish, poultry, insecticides, fungicides, pesticides, and vaccines containing thimerosal. The most frequent exposures are from consumption of fish holding $\mathrm{MeHg}(\mathrm{CH} 3 \mathrm{Hg}+)$ and prophylaxis used from vaccines containing preservative thimerosal which is rapidly metabolized to EtHg $(\mathrm{C} 2 \mathrm{H} 5 \mathrm{Hg}+)$. Thimerosal-containing vaccines (TCV) increase the risk of cumulative exposure to EtHg which occurs together with $\mathrm{MeHg}$ from fish, which in some cases can cause neurological effects [12]. A number of studies have shown an association between organic-Hg exposure and an increased risk of neurodevelopmental disorders, such as tic disorders, ASD, attention-definition/hyperactivity disorder (ADHD), and delayed language/speech skills. During this time, the organic $\mathrm{Hg}$ form stored in the brain is metabolized to mercury $\mathrm{Hg}(\mathrm{Hg} 2+)$ [13].

\section{Toxicity of mercury}

The most sources of mercury exposure are seafood and dental amalgam. $\mathrm{Hg}$ salts have immunomodulatory and allergen properties, which genetically stimulate autoimmune in susceptible animals, and can enhance autoimmune development in humans, as well as can induce immune-stimulation, hypersensitivity and autoimmunity. In patients diagnosed with ASD, mercury appears to be one of the main environmental triggers for inflammation of neuroin and autoimmunity. Methyl mercury is also associated with severe neurological disorders in children affected before birth when their mothers consume grains or seafood contaminated with mercury [7].

All components of mercury in the form of methyl and alkyl which enter the human body continuously will cause permanent damage to the brain, liver and kidneys [14]. The effects of mercury toxicity on humans depend on the chemical form of mercury, dosage, age of people exposed, length of exposure, entry into the body, fish diet and seafood consumption. For example, the form of mercury $(\mathrm{HgCl} 2)$ is more toxic than mercuro $(\mathrm{HgCl})$, this is because the divalent form dissolves more easily than the monovalent form. In addition, the form of $\mathrm{HgCl} 2$ is fast and easily absorbed so that its toxicity is higher. Organic forms such as methyl mercury, about $90 \%$ are absorbed by the intestinal wall, which is much greater than inorganic form $(\mathrm{HgCl} 2)$ that is only about $10 \%$. The organic form can also penetrate the barrier of blood and placenta so that it can cause teratogenic effects and nervous disorders [14].

Mercury vapour that is inhaled at very high concentrations may result in acute corrosive bronchitis and interstitial pneumonitis and, if not fatal, can be associated with effects on the central nervous system such as tremors or increased stimulation. The main effect of exposure to mercury vapour is on the central nervous system. The initial signs are not specific, and this condition has been called asthenic-vegetative syndrome or micromercurialism. Identification of the syndrome requires neurasthenic symptoms and three or more of the following clinical findings: tremor, thyroid enlargement, increased radioiodine in thyroid intake, labile pulse, tachycardia, dermographism, gingivitis, haematological changes, or increased excretion mercury in urine. Symptoms of tremor, gingivitis, and erethism (memory loss, increased excitability, insomnia, depression, and shyness) have become the main manifestations of mercury poisoning from inhaled mercury vapour. Sporadic examples of proteinuria and even nephritis syndrome can occur in people who are exposed to mercury vapour, especially workers who experience chronic exposure. The pathogenesis may be the same as the immunology that occurs after inorganic mercury exposure [7].

The kidneys are the main target organ for inorganic mercury [4]. Although high doses of mercury chloride are toxic directly to renal tubular cells, the exposure to chronic small doses of mercury salts can cause immunological glomerular disease. People who are exposed can cause proteiuria which can be eliminated after being removed from the exposure. The results showed that Mercury chloride increased kidney expression and these mercury-induced changes were significantly greater in women than in men. As a result, female rats showed higher renal mercury excretion and lower tubular damage than male rats [15].

The main effect on health in humans exposed to methyl mercury is neurotoxicity. The clinical manifestations of neurotoxicity include paraesthesia (numbness and itching around the mouth, lips) and ataxia, which are characterized by stiffness, tripping-like when walking, and difficult in swallowing and saying words. Other signs include neurasthenia, loss of vision and hearing, convulsions and tremors. These all can eventually develop into coma and death. Neuropathological observations have shown that the cerebrum and cerebellum cortex are selectively involved with focal necrosis in neurons, lysis, phagocytosis, and replacement by glial cells. The overall acute effect is cerebral edema, but can result in cerebral atrophy [16]. 


\section{Mechanism of toxicity}

Mercury compounds can cause poisoning in the body by various mechanisms. Various forms of $\mathrm{Hg}$ can attack thiol groups in proteins or membranes. After $\mathrm{Hg}$ is connected to one or more sulfur amino acid residues in proteins or membranes, physiological functions, metabolism can be weakened or blocked, oxidative stress occurs, damages $\mathrm{Ca}$ homeostasis, and changes in glutamate homeostasis. Various studies have reported on the mechanisms that may be involved in sub-cellular neurotoxicity $\mathrm{MeHg}$. Methethylation of $\mathrm{MeHg}$ occurs in glial cells and then $\mathrm{Hg}$ is transferred to neurons and contributes to $\mathrm{MeHg}$ neurotoxicity [4].

The binding of high affinity divalent mercury to the sulfidril protein group in cells is an important mechanism for causing nonspecific cell injury or even cell death. Other common mechanisms are such as cessation of microtubule formation, enzyme inhibition, oxidative stress, cessation of protein and DNA synthesis, and autoimmune responses. Mercury causes changes in genes associated with glutathione and metallothionine systems in tissues.

Mercury causes mitochondrial dysfunction and oxidative stress. The malfunction of primary mitochondria in the ubiquinone-cytokron section and NADH dehydrogenase causes the transfer of Fe $2+$ and $\mathrm{Cu}+$ ions to the centre of a3Cub cytochrome $\mathrm{C}$. This can lead to depolarization and autoxidation of the inner mitochondria with fat peroxide and non-functioning of mitochondria [17]. Physiologically, there is an increase in hydrogen peroxide, lipid peroxide, and a decrease in mitochondrial glutathione levels by more than 50\%, pyridine nucleotide oxidation such as NAD (p) $\mathrm{H}$ and alter haemostatic calcium [18]. The physiological processes of mercury toxicity, mitochondrial dysfunction and oxidative stress are presented in Figure 1.

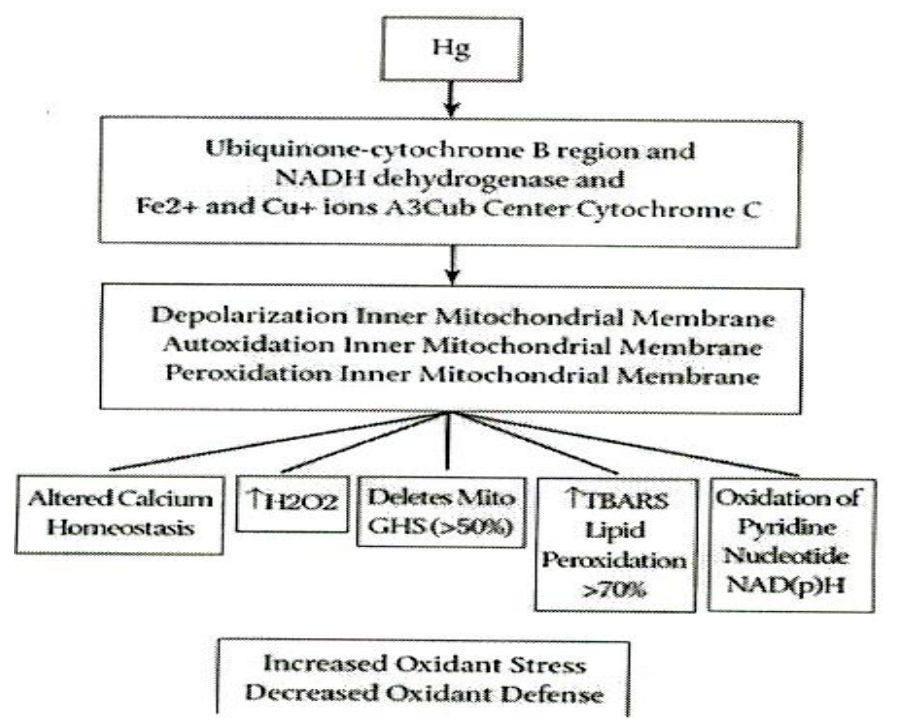

Figure 1. Physiological processes of mercury toxicity, mitochondrial dysfunction and oxidative stress [17]

The initial life phase which is particularly vulnerable to mercury poisoning is a sensitive sub population. In Minamata, Japan, pregnant women who consume fish that are contaminated with methyl mercury, provide mild symptoms, but give birth to babies who suffer from severe developmental disabilities, giving rise to initial concern about mercury as a poison in fetal development. Methyl mercury crosses the placenta and reaches the fetus, concentrated to the fetal brain at least 5-7 times the concentration in the mother's blood. High prenatal methyl mercury exposure can cause widespread damage to the fetal brain. However, the effects observed from low level exposure are inconsistent [18].

The safety of thimerosal (ethyl mercury) used in vaccines in childhood also received extensive attention. Recent reviews show that thimerosal is safe at the dosage used in vaccines, except the potential for local hypersensitivity. However, some babies can be exposed to mercury that accumulates during the first six months of life which can exceed the dosage recommended by the EPA. Steps have been taken quickly to remove thimerosal from vaccines in the United States through switching to single dose vials that do not require preservatives. Nonetheless, WHO states that using thimerosal in vaccines is safe and can be continued. This is important for developing countries where they use vials. A summary of the toxicology of mercury is presented in Table 2. 
Table 2. Toxicology of mercury [19]

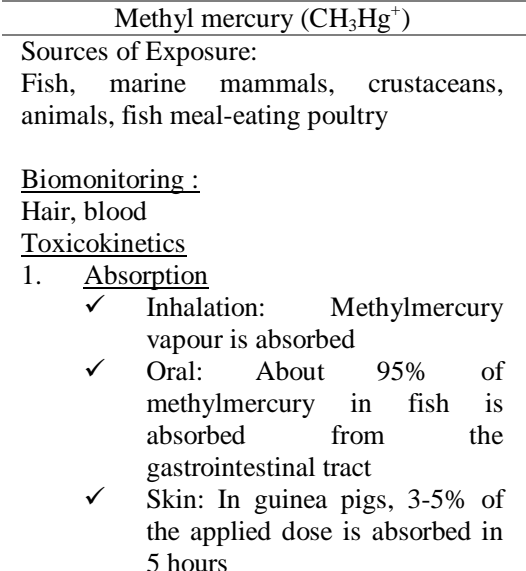

2. Distribution:

$\frac{}{\checkmark \quad \text { spread }}$ throughout the body because it is lipophilic, about 1 $10 \%$ is absorbed and spread to the blood, $90 \%$ in the blood is in erythrocytes. The $\mathrm{MeHg}$ cysteine complex is involved in $\mathrm{MeHg}$ transformation in cells.

$\checkmark \quad$ Half-life in blood $50 \mathrm{~d}, 50 \%$ dose is found in the liver, where $10 \%$ is in the brain.

$\checkmark$ Easily cross the blood of the brain and placenta

3. Biotransformation:

$\checkmark \quad \mathrm{MeHg}$ slowly demethylates to mercuric $\mathrm{Hg}\left(\mathrm{Hg}^{2+}\right)$

$\checkmark$ Macrophage tissue, intestinal flora, and fetal liver are sites of demethylation tissue

4. Excretion:

About $1 \%$ every day, it can be removed from the body. The main excretion in bile and feces. $90 \%$ is excreted in feces as $\mathrm{Hg}^{2+}$ and $10 \%$ in urine

5. Half-Time

70-80 d depending on species, dosage, sex and type of animal

6. Toxicodynamic

$\checkmark \quad$ Target on brain organ, adult and fetus

$\checkmark$ Causes of poisoning Demitylated $\mathrm{MeHg}$ to $\mathrm{Hg}^{2+}$ and $\mathrm{MeHg}$ toxicity

7. Medication: DMPS,DMSA

Element mercury $\left(\mathrm{Hg}^{0}\right)$

Sources of Exposure:

Dental amalgam, occupational exposure, religious ceremonies, fossil fuels, incenarator

Biomonitoring :

Urine, blood

$\underline{\text { Toxicokinetics }}$

1. Absorption

$\checkmark \quad$ Inhalation: About $80 \% \mathrm{Hg}^{0}$ is easily absorbed through inhalation.

$\checkmark \quad$ Oral: Absorption of $\mathrm{Hg}$ metal in the gastrointestinal tract is slight, each vapour in GI is converted to mercury sulfide and excreted

$\checkmark \quad$ Skin: the average rate of $\mathrm{Hg}^{0}$ absorption through human skin is $0.024 \mathrm{ng} / \mathrm{cm}^{2}$ for every $1 \mathrm{mg} / \mathrm{m} 3$ in air

2. Distribution :

$\checkmark \quad$ Quickly spread throughout the body due to lipophilic

$\checkmark \quad$ Half-life in blood 45d (slow phase), beak increases with increasing dose

$\checkmark$ Easily cross the blood of the brain and placenta

3. Biotransformation:

$\checkmark \mathrm{Hg}^{0}$ in tissue and blood is oxidized to $\mathrm{Hg}^{2+}$ by catalase and hydrogen peroxide $\left(\mathrm{H}_{2} \mathrm{O}_{2}\right)$

4. Excretion:

In the form of $\mathrm{Hg}^{0}$ excreted in air, sweat and saliva and as $\mathrm{Hg}^{2+}$ in feces and urine

5. Half-Time

$58 \mathrm{~d}$

6. Toxicodynamic

$\checkmark \quad$ Target on kidney and brain organs

$\checkmark$ Causes of poisoning $\mathrm{Hg}^{0}$ oxidation to $\mathrm{Hg}^{2+}$

7. Medication:

Becoming $\mathrm{Hg}^{2+}$; DMPS, DMPA after oxidation
Mercuric mercury $\left(\mathrm{Hg}^{2+}\right)$

Sources of Exposure:

Oxidation of mercury elements or demethylation of methyl mercury, intended / unintended $\mathrm{HgCl} 2$ poisoning Biomonitoring :

Urine, blood

Toxicokinetics

1. Absorption

$\checkmark$ Inhalation: Aerosol $\mathrm{HgCl}_{2}$ is absorbed

$\checkmark$ Oral:

$7-15 \%$ of ingested $\mathrm{HgCl}_{2}$ is absorbed from the GI. The absorption is according to the proportion of solubility in mercury brine. The absorption by neonates is greater than in adults

$\checkmark \quad$ Skin: In guinea pigs, 2-3\% of the applied dose of $\mathrm{HgCl}_{2}$ is absorbed

2. Distribution:

$\checkmark$ The highest accumulation is in the kidney; a small portion of the dose is maintained bound to the kidneys

$\checkmark$ Half-life in blood is 19.7-65.6 d. First phase is $24 \mathrm{~d}$ while the second phase is $15-30 \mathrm{~d}$.

$\checkmark \quad$ It is not easy to penetrate brain blood or placenta. In mercuric neonates, $\mathrm{Hg}$ is not concentrated in the kidneys. It is more widely distributed to other tissues. In the fetal and neonatal blood barrier, the brain is formed incompletely so that the $\mathrm{Hg}$ mercuric concentration of the brain is higher compared to adults.

3. Biotransformation:

$\checkmark \quad \mathrm{Hg}^{0}$ vapours are exhaled by rats from mercuric $\mathrm{Hg}$.

$\checkmark$ Mercuric $\mathrm{Hg}$ is not methylated in body tissues but GI microorganisms can form $\mathrm{MeHg}$.

4. Excretion:

Excreted in feces and urine, saliva, bile, sweat, air and breast milk

5. Half-Time 1-2Mo

6. Toxicodynamic

$\checkmark \quad$ Target on kidney organ

$\checkmark$ Cause of poisoning $\mathrm{Hg}^{2+}$ binding to thiol in enzymes and proteins

7. Medication:

DMPS, DMSA

\section{The effects of mercury on health}

- The effects on the central nervous system (CNS)

CNS is the main target of mercury toxicity. The neurotoxic effects of $\mathrm{Hg}$ exposure involve many interrelated mechanisms that ultimately lead to cell damage. Hg induces dysfunction in several organs, 
including mitochondria, endoplasmic reticulum, and acid components. $\mathrm{Hg}$ can activate vascular endothelial growth factor (VEGF) and release IL-6 from human mast cells, which can contribute significantly to blood-brain barrier disorders and brain inflammation [7].

Mercury vapour exposure shows a variety of cognitive, sensory, personality and motor function effects. Persistent effects (tremor, cognitive, deficits) occur in workers who have been exposed to 10-30 years. One study reported that workers who were exposed to mercury more than $0.1 \mathrm{mg} / \mathrm{m} 3$ improve symptoms of dysfunction in the central nervous system. The effects on the central nervous system can occur in workers exposed to long-term mercury vapour at exposure levels of $\geq 20 \mu \mathrm{g} / \mathrm{m} 3$ [20].

Methyl mercury attacks the central nervous system with the brain as the main organ target. The data shows that the developing brain of the fetus has a higher sensitivity than adults. This mechanism is associated with an increase in toxic substances in reactive oxygen species (ROS) which are associated with the etiology of neurodegenerative diseases such as amyotrophic lateral sclerosis, Parkinson's disease, and Alzheimer's disease. Over the past few decades, toxic effects of mercury have been linked primarily to the central nervous system [10].

Figure 2 illustrates the presence of lesion areas in several zones of the nervous system that show symptoms of Minamata disease due to exposure to mercury. Lesions in the cerebellum (1) result in loss of balance (ataxia) and speech disorders (dysarthria). Impaired vision occurs in the narrowing of the field, visual difficulties in the periphery due to damage to the occipital lobe (2). Sensory disorders or stereo anaesthesia occur due to damage to postcentral gyrus (3). Muscle weakness, cramps or movement disorders are signs of damage to precentral gyrus (4). Hearing difficulties are caused by disturbances in the temporal region of the transverse gyrus (5). Complaints occurs on difficulty and sensory disturbances such as pain, touch or temperature due to interference with sensory nerves (6).

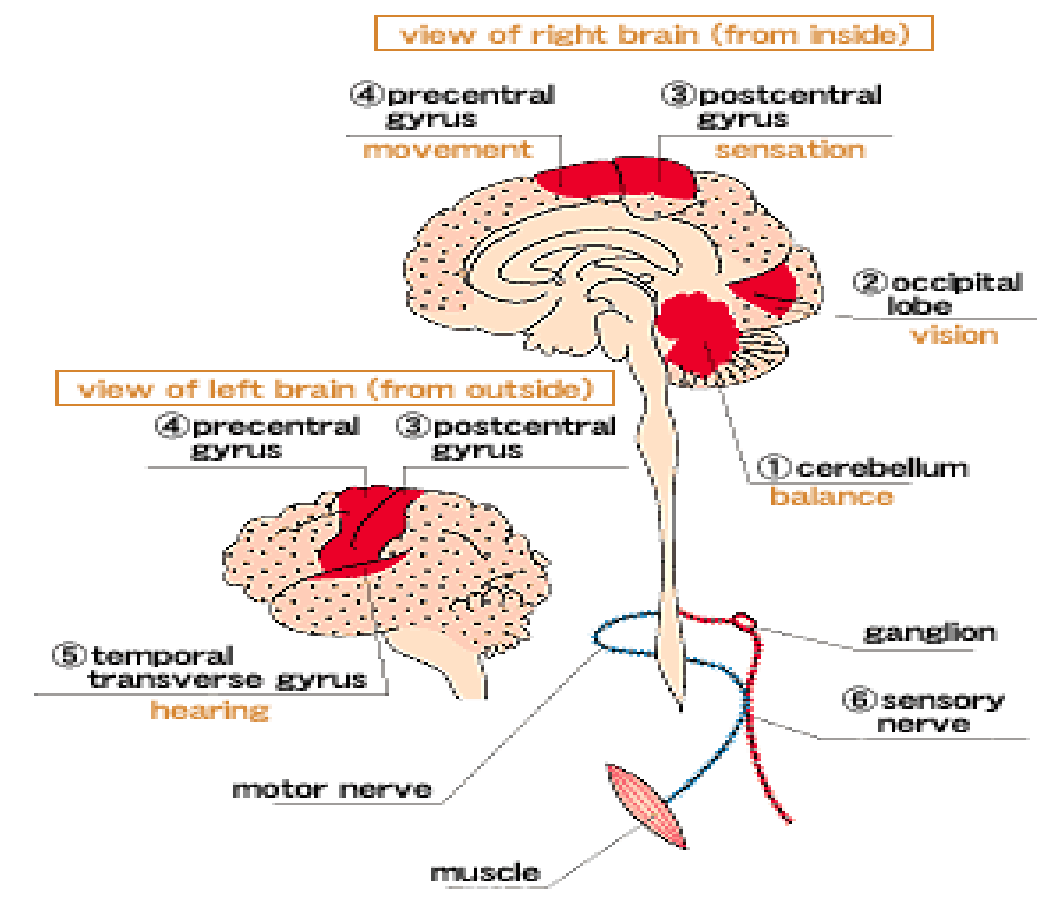

Figure 2. Injury to the nervous system due to methyl mercury (National institute of minamata disease, NIMD-Japan) [19]

- The effect on ASD (autism spectrum disorder)

The results showed that $\mathrm{Hg}$ significantly reduced neuronal migration due to modulation of cytokine production (IL-6, TNF- $\alpha$ ). The production of TNF-alpha induced by $\mathrm{Hg}$ in the brain has a significant impact on the development of ASD [7]. Mercury is highly toxic metal that will be trigger the formation of reactive oxygen species (ROS), and cause oxidative stress, this condition can be damage DNA and apoptosis occurs so that it can cause ASD (Autism Spectrum Disorder). Prenatal and early-life exposures to Hg have been hypothesized to be associated with increased risk of autism spectrum disorders (ASD). 


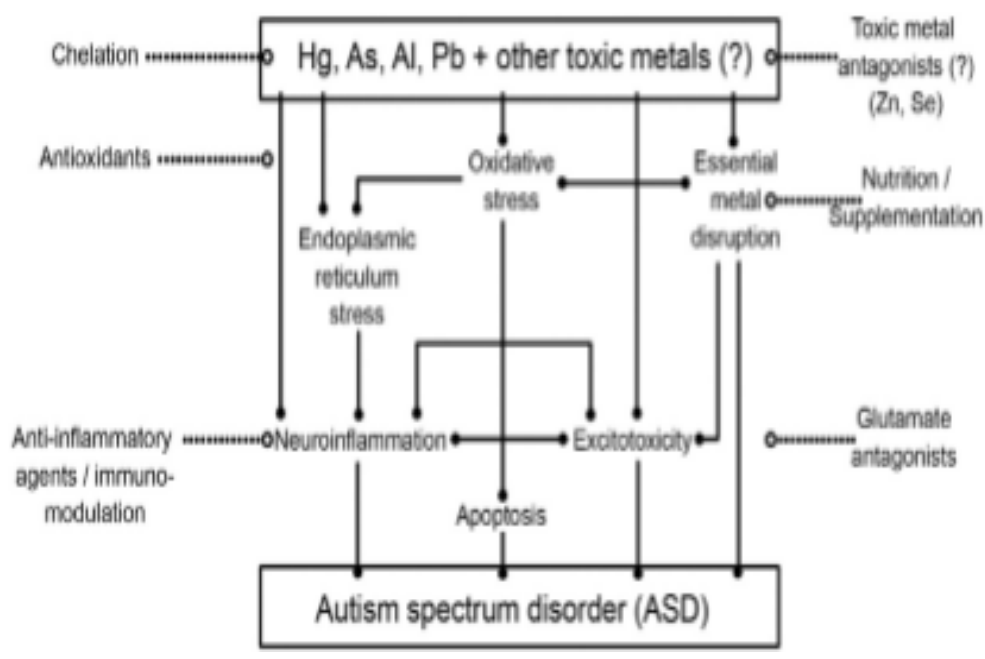

Figure 3. Mechanism of the Roles of Mercury in the Development of ASD (Autism Spectrum Disorder) [7]

- $\quad$ The effect on cancer (Neoplasma)

There is no single epidemiological study that found a correlation between $\mathrm{Hg}$ exposure and cancer, but two studies found the correlation between $\mathrm{Hg}$ exposure and acute leukaemia. The interpretation of results is still difficult because of the small population. Several studies of experimental animals with chronic exposure to $\mathrm{MeHg}$ increased the incidence of kidney tumours in male mice. The cancer research agency (IARC) and the environmental protection Agency (EPA) of the United States have classified $\mathrm{MeHg}$ as a possible human carcinogen.

- The effect on cardiovascular

A study showed that mercury exposure is associated with an increased risk of hypertension, myocardial infarction, coronary dysfunction, and atherosclerosis [18]. The research shows that exposure to mercury can increase the risk of cardiovascular disease. Also, mercury toxicity is strongly correlated with hypertension, coronary heart disease, myocardial infarction, cardiac arrhythmias, carotid artery obstruction, cerebrovascular accidents, and general atherosclerosis [10]. $\mathrm{Hg}$ is considered an important risk factor for cardiovascular disease, playing a role in the development of cardiovascular events.

- The effect on blood profile

Mercury can cause haemolysis and pose a risk of anaemia. Mercury triggers a complex reaction that leads to cell damage and ends in cell death. When mercury enters erythrocytes, there is an increase in osmotic pressure in the cell, a decrease in the antioxidant activity of the membrane and an increase in the prooxid activity of the cytosol. Decreased membrane antioxidant activity and increased prooxidant activity of the cytosol lead to peroxidative destruction of erythrocyte membranes which combines with increased osmotic pressure resulting in the release of haemoglobin namely haemolysis [20].

Research on animals exposed to mercury raises the risk of anemia and clotting abnormalities. Anaemia is associated with a decrease in GPx activity, as well as clotting abnormalities or typical platelet disease in the presence of massive bleeding due to low blood clotting factors is also associated with a decrease in GPx enzyme activity. Glutathione peroxidase (GPx) has an important function in the process of aerobic glycolysis on the pentose pospate pathway which is the main energy source for the synthesis of erythrocytes. Decreasing GPx activity will inhibit the glycolysis process which results in reduced energy from reduced erythrocytes, which shortens the age of erythrocytes, whose weight depends on the quantity of these enzymes. GPx has the ability to protect blood cells from damage and oxidative stress. Mercury in the body is a free radical that can cause depletion of GSH supplies and accumulation of $\mathrm{H}_{2} \mathrm{O}_{2}$ so that it shortens the age of erythrocytes which cause oxidative damage in cell membranes resulting in haemolysis [21].

Mercury exposure can increase free radical production [22]. Mitochondrial dysfunction and oxidative stress [19]. Superoxide Dismutase, Catalase and Glutathione are enzymes that can protect erythrocytes from stress and oxidative damage [21]. During the course of metabolism, strong oxidants occur, both in blood cells and in other body cells. These oxidants include superoxide (O2- $\bullet$ ), hydrogen peroxide $(\mathrm{H} 2 \mathrm{O} 2)$, peroxyl radicals $(\bullet \mathrm{OOH})$, and hydroxyl radicals $(\bullet \mathrm{OH})$. These oxidants are referred to as ROS.

Superoxide is formed in erythrocytes by the auto-oxidation process of haemoglobin to methemoglobin, every day about $3 \%$ of haemoglobin in human erythrocytes is thought to experience auto-oxidation. Superoxide spontaneously undergoes dismutase so that $\mathrm{H} 2 \mathrm{O} 2$ and $\mathrm{O} 2$ are formed. 
If the superoxide dismutase (SOD) enzyme concentration is high, the reaction will run quickly. $\mathrm{H} 2 \mathrm{O} 2$ formed will be converted to $\mathrm{H} 2 \mathrm{O}+\mathrm{O} 2$ by the catalase (CAT) enzyme. The role of the glutathione peroxidase (GPx) enzyme is to catalyse reduced glutathione (GSH)+H2O2 into oxidized glutathione (GSSH) and $\mathrm{H} 2 \mathrm{O}$. The interaction of mercury in erythrocytes is shown in Figure 4.

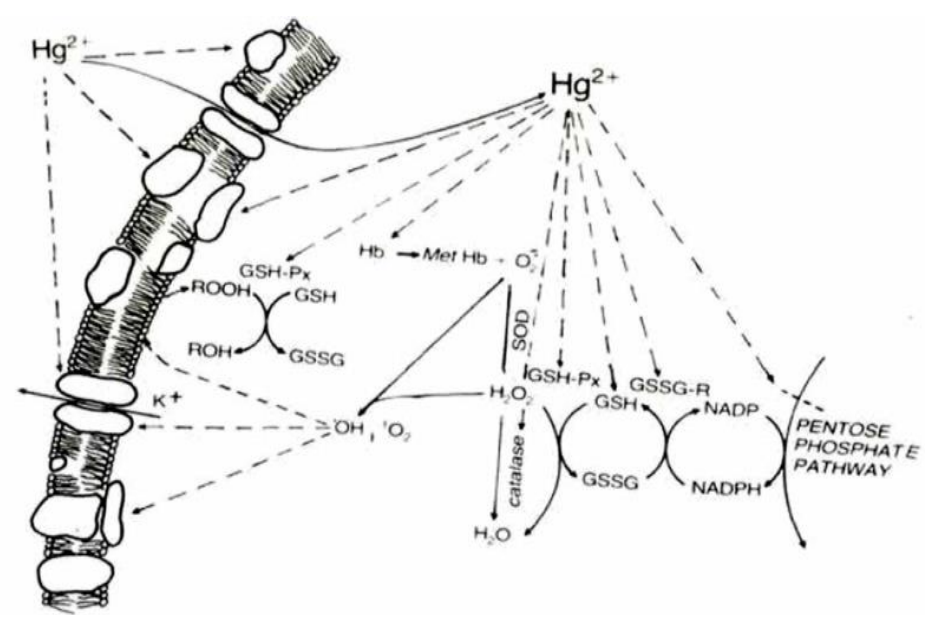

Figure 4. Interaction of mercury in erythrocytes [19]

- The effect on immune system

The body's immune system appears to be sensitive to mercury, although there is no data yet on the effect of mercury on the immune function of the human body. The effect of mercury on the immune system of the human body has not been studied, but mercury exposure has been found to change certain immune parameters. Kim Hyun sang et al. examined mice that were exposed to $\mathrm{Hg}$ continuously with various doses in drinking water for 14 days, at the highest dose $(37.5 \mathrm{ppm})$ the body weight decreased, the kidneys and spleen grew, blood leukocyte levels increased. Mercury levels of 1.5-37.5 ppm, CD3 $+\mathrm{T}$ levels of lymphocytes in the spleen decreased, single-positive CD4 + and CD8 + lymphocytes decreased. In addition, research in Brazil involving 33 workers resulted urine mercury levels $50 \mu \mathrm{g} / \mathrm{g}$ creatinine, CD4 + lymphocytes decreased, B lymphocytes significantly decreased. Serum analysis of immunoglobulin $\mathrm{E}$ antibodies is increased but does not detect anti-DNA or anti-nucleolar antibodies [23].

- The Effect on Reproductive and Developmental Disorders

A study reported that men who were exposed to mercury would increase the incidence of spontaneous abortion in their wives. Husband's urine mercury concentration above $50 \mathrm{mg} / \mathrm{L}$ has a-two times-risk for spontaneous abortion in his wife [23]. The relationship between mercury exposure and reproductive effects in female workers in China has caused long-term and menstrual dysfunction disorders, menstrual blood volume and dysmenorrhea, hypertension due to pregnancy, stillbirth, low birth weight and birth defects. The respondents who were exposed when compared with controls had a risk of two times long dysfunction disorders and menstrual cycles, 2x dysmenorrhea, 2x hypertension due to pregnancy, $2.5 \mathrm{x}$ stillbirths, three times low birth babies, and 2.6x birth defects [23].

- The effect on genes

Studies on humans have shown that mercury exposure causes genetic damage. Some researchers report chromosomal abnormalities are more common in workers exposed to mercury in elemental or inorganic form. In a recent study, it is reported that there is a significant increase in micro-nuclei in workers exposed to mercury when compared with controls not exposed. Franchi et.al. in the National Research Council reported that there is a correlation between micro-nuclei in peripheral lymphocytes and mercury concentrations in blood in fishing populations contaminated with mercury for eating seafood [23].

- The effect on antioxidant status

Mercury has a strong affinity for thiol or sulfidril [7]. Hormones and enzymes are compounds that contain thiol groups so that they are easily bound by mercury. Mercury will bind to thiol groups found in antioxidant proteins which reduce intracellular thiol content leading to antioxidant activity decrease. This condition causes the work activities of antioxidant enzymes and non-enzymes to be inhibited so that there is thinning of glutathione and an increase in $\mathrm{H} 2 \mathrm{O} 2[8,10]$. 
The exposure to mercury increases the production of free radicals, potentially because of the role of mercury in the Fenton reaction and a reduction in the activity of antioxidant enzymes, such as glutathione peroxidase [10]. Superoxide dismutase (SOD), catalase (CAT) and glutathione peroxidase (GPx) are antioxidant enzymes. SOD functions as a catalyst in breaking down superoxide (O2 - -) into $\mathrm{H} 2 \mathrm{O} 2$ and catalase will break it down into water and oxygen, therefore any changes in the activity of the two enzymes can cause a number of damaging effects due to the accumulation of superoxide radicals and $\mathrm{H} 2 \mathrm{O} 2$. Mercury can inhibit enzyme activity such as superoxide dismutase, catalase and glutathione peroxidase [24]. In conditions where the level of endogenous antioxidants decreases, more exogenous antioxidants are needed in order to eliminate $\operatorname{ROS}[25,26]$. Glutathione peroxidase (GPx) functions as a catalyst in breaking down $\mathrm{H} 2 \mathrm{O} 2$ into oxidized glutathione $(\mathrm{GSSH})$ using glutathione $(\mathrm{GSH})$ as a substrate [21]. Mercury will bind to the thiol group so that it will disrupt the GPx enzyme activity and cause a decrease in the levels of reduced glutathione (GSH) and $\mathrm{H} 2 \mathrm{O} 2$ buildup. Mercury exposure can increase free radical production, ROS, superoxide anions and fenton reactions [10]. The roles of mercury in antioxidant status and lipid peroxidation is shown in Figure 5.

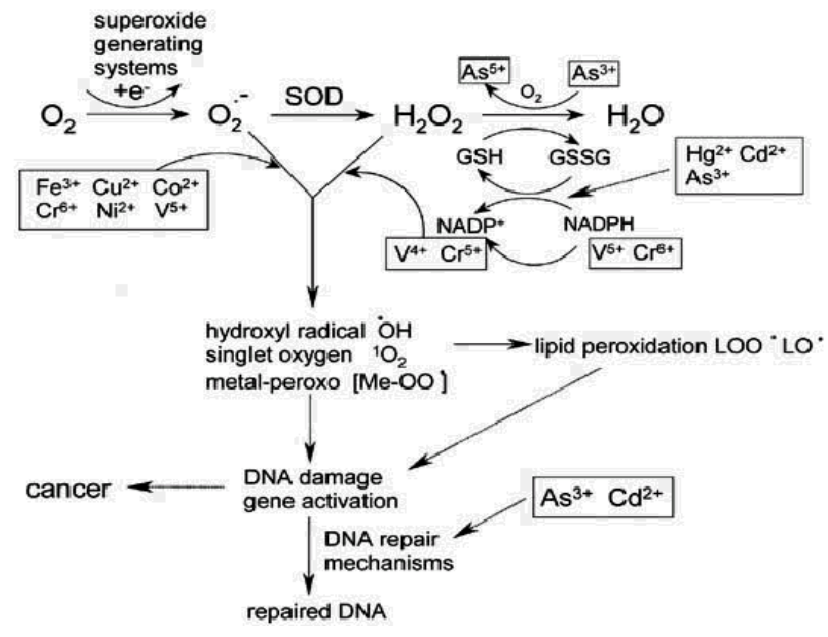

Figure 5. The Roles of mercury on antioxidant Status and lipid peroxidation [27]

- The effect on lipid peroxidation

Mercury is a very toxic metal. This compound can trigger the formation of ROS, hydrogen peroxide, lipid peroxidation, hydroxyl radicals which are all free radicals that can inhibit enzymes, cell damage, DNA damage, protein structure damage, disruption on the body's antioxidant metabolism, especially superoxide dismutase (SOD) and glutathione peroxidase (GPx) [2, 18]. Hydrogen peroxide formed when reacting with transition metals (transitional metals) such as $\mathrm{Fe}++$ and $\mathrm{Cu}+$ in a Fenton reaction will produce the most dangerous hydroxyl radical $(\bullet \mathrm{OH})$ because the reactivity is very high [25]. Hydroxyl radicals can damage unsaturated fatty acids which are components of phospholipids which make up cell membranes that are rich in sources of polyunsaturated fatty acids (PUFA) so that they may lead to lipid peroxidation. Lipid peroxidation products are measured by plasma levels of malondialdehyde (MDA). MDA is one of the polyunsaturated lipid acid peroxidation products in cell membranes. The increase of MDA levels is an important indicator of the occurrence of lipid peroxidation [25]. Lipid peroxidation is a chemical mechanism that interferes with the structure and function of membranes which occur as a result of free radical attacks on lipids. The ability of mercury to produce ROS can be indicated by plasma MDA levels. High levels of MDA in plasma can be used as a sign that the levels of free radicals in the body are high [25].

Mercury in the body is also able to inhibit methionine synthase (SM) in the methionine cycle, thereby it may interfere with GSH synthesis, causing a decrease in GSH levels [17]. Glutathione is an endogenous non-enzyme antioxidant that has thiol groups and is the target of mercury; 1 molecule of mercury can bind 2 glutathione molecules, so the presence of mercury in the blood will have an effect on thinning glutathione and an increase in $\mathrm{H} 2 \mathrm{O} 2$ resulting in lipid peroxidation and oxidative stress. Mercury is a free radical, this substance will bind thiol or sulfhydryl contained in antioxidant proteins so the antioxidant activity will decrease $[28,29]$. The figure for the roles of mercury in the methionine cycle is presented in Figure 6. 


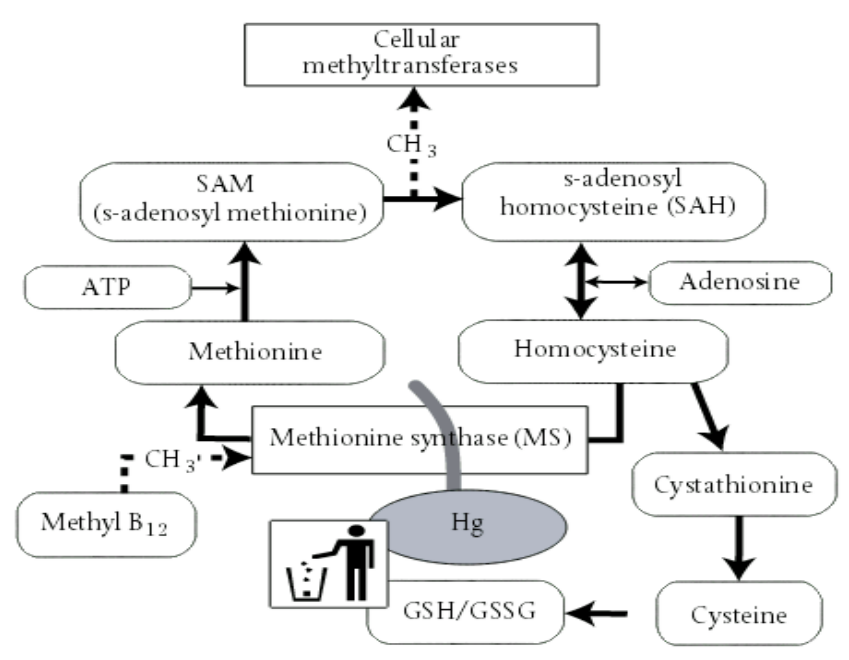

Figure 6. Roles of mercury in methionine cycle [17]

- The effect another

However, the available data appear to show an association between exposure to $\mathrm{Hg}$ and an increase in incidence and severity of renal disease [30]. Mercury is a highly toxic metal that directly affects the nervous and cardiovascular system. There is a relationship between mercury levels in hair and urine with protein levels, hemoglobin and hematocrit levels. High urinary and hair mercury levels, show proteinuria and low hemoglobin and hematocrit concentrations [31]. Metyl mercury ( $\mathrm{MeHg}$ ) is a well-known neurotoxin, with particularly high tox-icity in the nervous system, because it accumulates to high levels in astrocytes which account for approx-imately 50\% of the central nervous system (CNS) [32]. Exposure to mercury during pregnancy was associated with early reductions in BPD (biparietal diameter) (BPD) [33]. Mercury exposure represents a significant concern during the course of pregnancy, because of the riskto the fetus. In particular, $\mathrm{MeHg}$ readily passes across the placental barrier to the fetus where, binding to hemoglobin, its main ligand in red blood cells, it reaches blood concentrations higher than those of the mother [34].

Mercury can cause serious injury by protein damage and depletion of thiol-containing antioxidants and consequently oxidative stress-mediated liver injury [35]. Heavy metals such as cadmium (Cd), mercury $(\mathrm{Hg})$, lead $(\mathrm{Pb})$, chromium $(\mathrm{Cr})$, and arsenic (As) showed a close association to breast cancer. Heavy metal, it as a contributing factor of carcinogenicity. There is a strong correlation between cancer rate and metal exposure, lung cancer is associated with the occupational exposure to metals including cadmium, chromium, nickel, copper, cobalt, lead, and mercury. Mercury exposures are associated with prostate and bladder cancers [36]. Hg exposure could trigger epigenetic alterations, hence leading to various human disorders including reduced newborn cerebellum size, adverse behavioral outcomes, atherosclerosis and myocardial infarction. Similarly, in adults, occupational $\mathrm{Hg}$ exposure has been associated with an increased risk of autoimmunity. It has been revealed that miRNAs in the woman's cervix are a novel responder to maternal $\mathrm{Hg}$ exposure during pregnancy. $\mathrm{Hg}$-induced epigenetic alterations analysis of kidney tissues showed a significant interruption in renal function. DNA methylation and histone post-translation modifications are predominant types of $\mathrm{Hg}$ epigenetic alterations [37]. Pregnant women who eat methyl mercury-contaminated fish endanger the development of the peripheral and central nervous system of the fetus; this can lead to mental retardation, delayed development, speech disorders, seizures and impaired memory [38]. Previous studies have reported that prenatal exposure to $\mathrm{MeHg}$ is associated with low birth weight, delayed neurodevelopment, and growth and development of children. Suboptimal fetal growth has been adversely associated with neu- rodevelopment in childhood and it has been associated with an increased risk of chronic diseases in adulthood, including meta- bolic syndrome [39]. Study on the direct relationship between $\mathrm{Hg}$ exposure, inflammation, and cardiovascular disorders should be at highest importancein future investigations. Toxic effects of $\mathrm{Hg}$ on the skin which could lead to various diseases such as pink disease or acrodynia, $\mathrm{Hg}$ exanthema and contact dermatitis [40]. In traditional gold miners areas, the main source of exposure to mercury is usually inhalation of the vapours released from the gold processing activities especially from smelting amalgams. Elemental mercury becomes highly toxic when it vapourizes and is inhaled into the lungs. The vapourized mercury crosses the alveolar blood-gas barrier and accumulates in different tissues including the kidneys and the brain. Approximately $80 \%$ of inhaled dose of mercury is retained in the human body and gets distributed into the tissues through blood circulation [41]. 


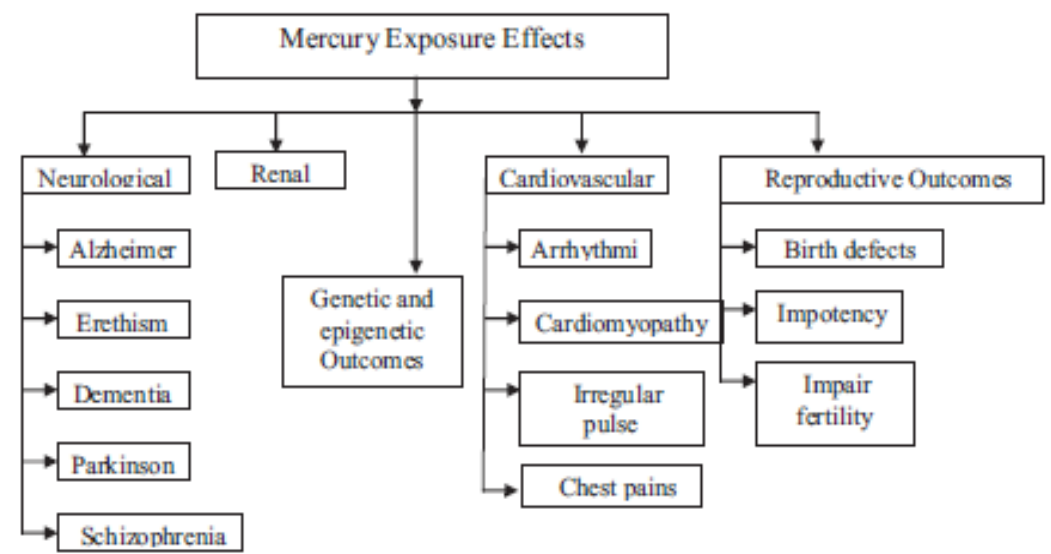

Figure 7. Human health effects induced by exposure to mercury [42]

\section{CONCLUSION}

Mercury is one of the widespread toxic metals with serious health risks to humans. Exposure to $\mathrm{Hg}$ also occurs via other routes like ingestion, inhalation, dental amalgams, and dermal contact. Generally, exposure to small amounts of mercury can cause serious health problems in humans. Mercury is still widely used by traditional gold miners illegally. Mercury exposure causes Epigenetic mechanisms, alteration in the DNA methylation, adverse health effect as nervous system, cardiovascular system, endocrine system and immune system, ASD (Autism Spectrum Disorder), cancer, reproductive disorders and development, genes, decreased antioxidant status and lipid peroxidation.

\section{ACKNOWLEDGEMENTS}

The researchers would like to thank Faculty of Medicine Unissula Semarang.

\section{REFERENCES}

[1] Dewi N.R., Onny S, Suhartono, "Relationship of Mercury Exposure History to Body Balance Disorders in Traditional Gold Miners in Jendi Village Selogiri District Wonogiri Regency (In Bahasa Indonesia)," Jurnal Kesehatan Lingkungan Indonesia, vol. 12, no. 1, pp. 70-74, 2013.

[2] Afriza D., "The Effect of Mercury Vapour and the Role of Green Tea Extract on Brain cells," Journal of Dentistry Indonesia, vol. 20, no. 2, pp. 39-45. 2013.

[3] Bjørklund G., Maryam D., Joachim M., Jan A., "The toxicology of mercury: Current research and emerging trends," Environmental Research, vol. 159, pp. 545-554, 2017.

[4] Varadharajan V, Ganesan J., "Restoration Of Antioxidant Avtivity By N-Acetylcysteine and Gallic Acid on Kidney Tissue of Mercury Chloride intoxicated Wistar Rats," International Journal of Biological \& Pharmaceutical Research, vol. 4, pp. 302-7. 2013.

[5] UNEP, Global Mercury Assessment : Sources, Emissions, Releases and Environmental Transport. p. 24-7, 2013.

[6] KESDAM. Rencana Aksi Nasional penghapusan Penggunanan Merkuri pada Pengolahan Emas 2014-2018. 2014

[7] Bjørklund D., et al., "Toxic metal (loid)-based pollutants and their possible role in autism spectrum disorder," Environmental Researc, vol. 166, pp. 234-25, 2018.

[8] Zulaikhah S.T., Anies, Suwondo A., Santosa, "Effects of Tender Coconut Water on Antioxidant Enzymatic Superoxida Dismutase (SOD), CATALASE (CAT), Glutathione Peroxidase (GPx) and Lipid Peroxidation In Mercury Exposure Workers,” International Journal of Science and Researc, vol. 4, no. 12, pp. 515-524, 2015.

[9] Crowe, W., et al., "Mercury as an environmental stimulus in the development of autoimmunity-a systematic review," Autoimmun Rev., vol. 16, pp. 72-80, 2017.

[10] Genchi G., Maria S.S., Alessia C. Graziantonio L., Alessia C., "Mercury Exposure and Heart Diseases, Review," Int. J. Environ. Res. Public Health, vol. 14, no. 74, 2017.

[11] Kretsinger RH., Vladimir NU., Eugene AP., "Mercury, Physical and Chemical Properties," Encylopedia Metalloproteins, 2013.

[12] Dórea, J.G., "Low-dose Thimerosal in pediatric vaccines: adverse effects in perspective," Environ. Res., vol. 152, pp. 280-29, 2017.

[13] Berlin, M., Zalups, et.al., “(Eds.), Handbook on the Toxicology of Metals, Specific Metals II,” Academic Press, pp. 1013-1075, Amsterdam 2015. 
[14] Alfian Z., "Merkuri: Antara Manfaat dan Efek Penggunannnya bagi Kesehatan Manusia dan Lingkungan (In Bahasa Indonesia), Naskah Pidato Pengukuhan Guru Besar 2006.

[15] Hazelhoff MH., Romina PB., Alberto C., Adriana M.T., "Renal Expression Of Organic Anion Transporters Is Modified After Mercuric Chloride Exposure: Gender-Related Differences,” Toxicology Letters, 2018.

[16] Damin S., "Introduction to Chemistry: Medical Student Lecture Handbook and the Strata I Program of the Bioeksakta Faculty (In Bahasa Indonesia)," Jakarta: EGC 2009.

[17] Houston MC., "The role of mercury and cadmium heavy metals in vascular disease, hypertension, coronary heart disease and myocardial infarction," Alternative Therapies in Health and Medicine, vol. 13, pp. 128-33 2007.

[18] Counter SA, Buchanan LH., "Mercury exposure in children : A review," Toxicol Appl Pharmacol, vol. 198, pp. 209-30. 2004.

[19] WHO, "Exposure to Mercury : A Major Public Health,” In: Environment PH, editor. Genewa: World Health Organization 2007.

[20] Murray RK, Granner DK, Roadwell VW., "Harper's Illustrated Biochemistry," In: Wulandari N, Randy L, Dwijayanti L, Liena, Dany F, Rachman LY, editors. Biokimia Harper. $27^{\text {th }}$ ed. Jakarta: EGC. 2009

[21] Azevedo BF, Furieri LB, et.al., "Toxic Effects of Mercury on the Cardiovascular and central Nervous System : Review Article," Journal of Biomedicine and Biotechnology, pp. 1-11, 2012.

[22] NRC, "Effect of Metyhmercury Board on Environmental Studies and Toxicology Commision on Life Sciences. Toxicological Effect of Metyhmercury," Washington DC: National Academy Press, 2010.

[23] Al-azzawie HF, Umran A, Hyader NH., "Oxidative Stress, Antioxidant Status and DNA Damage in a Mercury Exposure Workers," British Journal of Pharmacology and Toxicology, vol. 4, no. 3, pp. 80-8, 2013.

[24] Winarsi H., "Natural \& Free Radical Antioxidants (In Bahasa Indonesia)," 3 ed. Yogyakarta: Kanisius, 2007.

[25] Astuti S., "Soy Isoflavones and Their Potential as Capture of Free Radicals (In Bahasa Indonesia)," Jurnal Teknologi Industri dan Hasil Pertanian, vol. 13, pp. 126-36, 2008.

[26] Valko M, Morris H, Cronin MTD., "Metals, Toxicity and Oxidative Stress," Current Topics in Medicinal Chemistry, vol. 12, pp.1161-208, 2005.

[27] Baker SM., "Who Ignores Individuality Fails the Patient," A Clinician's Journal New York, pp. 88-95, 2007.

[28] Zulaikhah ST, Wahyuwibowo J., "The Effect of Tender Coconut Water on Free Radical Due to Mercury Exposure," International Journal of Public Health Science (IJPHS), vol. 7, no. 2, pp. 102-106, 2018.

[29] L. Maslachah et al., "The Inhibition of Vitamin E ( $\alpha$-tocopherol) Antioxidant to Superoxide Radical Reactive Oxygen Species (O2'-) Production on the White Rat (Rattus norvegicus) Stressed by an Electric Shock," Media Kedokt. Hewan, vol. 24, no. 1, pp. 21-26, 2008.

[30] Bridges CC, Zalups RK., "The aging kidney and the nephrotoxic effects of mercury," J Toxicol Environ Heal - Part B Crit Rev., vol. 20, no. 2, pp. 55-80, 2017.

[31] Ekawanti A, Krisnayanti BD., "Effect of Mercury Exposure on Renal Function and Hematological Parameters among Artisanal and Small-scale Gold Miners at Sekotong, West Lombok, Indonesia," Journal Health Pollut., vol. 5, no. 9, pp. 25-32, 2015.

[32] Lee YH, Kang HM, Kim DH, Wang M, Jeong CB, Lee JS., "Adverse effects of methylmercury (MeHg) on life parameters, antioxidant systems, and MAPK signaling pathways in the copepod Tigriopus japonicus," Aquat Toxicol, vol. 184, pp. 133-41, 2017.

[33] Ballester F, Iñiguez C, Murcia M, Guxens M, Basterretxea M, Rebagliato M, et al., "Prenatal exposure to mercury and longitudinally assessed fetal growth: Relation and effect modifiers," Environ Res., vol. 160, pp. 97-106, 2018.

[34] Andreoli V, Sprovieri F., "Genetic aspects of susceptibility to mercury toxicity: An overview," Int. J. Environ. Res. Public Health, vol. 14, no. 1, 2017.

[35] Hazelhoff MH, Torres AM., "Gender differences in mercury-induced hepatotoxicity: Potential mechanisms," Chemosphere, vol. 202, pp. 330-8, 2018.

[36] Marouf B., "Association between serum heavy metals level and cancer incidence in darbandikhan and Kalar Area, Kurdistan Region, Iraq,” Niger J Clin Pract., vol. 21, no. 6, pp. 766-71, 2018.

[37] Khan F, Momtaz S, Abdollahi M., "The relationship between mercury exposure and epigenetic alterations regarding human health, risk assessment and diagnostic strategies," J. Trace Elem Med Biol. vol. 52, pp. 37-47, 2019

[38] Budnik LT, Casteleyn L., "Mercury pollution in modern times and its socio-medical consequences," Sci. Total Environ., vol. 654, pp. 720-34, 2019.

[39] Ha E, Basu N, Bose-O’Reilly S, Dórea JG, McSorley E, Sakamoto M, et al., "Current progress on understanding the impact of mercury on human health," Environ Res., vol. 152, pp. 419-33, 2017.

[40] Faheem Maqbool, Kamal Niaz,Fatima Ismail Hassan, FazlullahKhan and MA., "Immunotoxicity of mercury: Pathological and toxicological effects," J. Environ Sci Heal Part., vol. 37, no. 1, pp. 29-46, 2017.

[41] Gyamfi O, Sorenson PB, Darko G, Ansah E, Bak JL., "Human health risk assessment of exposure to indoor mercury vapour in a Ghanaian artisanal small-scale gold mining community," Chemosphere, vol. 241, 2020.

[42] Kim K-H, Kabir E, Jahan SA., "A review on the distribution of $\mathrm{Hg}$ in the environment and its human health impacts," J. Hazard Mater, vol. 306, pp. 376-85, 2016. 